\section{CVIA}

REVIEW ARTICLE

pISSN 2508-707X / eISSN 2508-7088 https://doi.org/10.22468/cvia.2017.00073 CVIA 2017;1(3):193-204

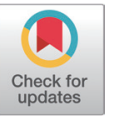

\title{
The Prognostic Role of T1 Mapping Sequences: Can T1 Mapping Parameters Have a Role in Risk Stratification?
}

\author{
Eui-Young Choi', Chul-Hwan Park², Tae Hoon Kim² \\ 'Division of Cardiology, Heart Center, Gangnam Severance Hospital, Yonsei University \\ College of Medicine, Seoul, Korea \\ 2Department of Radiology, Gangnam Severance Hospital, Yonsei University College of Medicine, \\ Seoul, Korea
}

Cardiovascular disease risk stratification and prognostication are very important for treatment planning. In addition, for a growing number of patients with overt symptomatic heart failure or asymptomatic but have structural heart disease, accurate risk stratification is essential. Conventional clinical cardiovascular risk factors, several biomarkers and echo-Doppler indexes are generally used to satisfy this need. However, non-invasive approaches to direct structural and tissue characterization of the myocardium have not produced satisfactory results. The recent development of the late gadolinium enhancement (LGE) imaging allows fibrosis or myocardial inflammation to be visualized. A growing body of evidence for LGEbased prognostication has been reported. However, not all patients with heart failure or at risk for it have been assessed with LGE. Moreover, the degree of diffuse fibrosis or inflammation cannot be easily quantified with LGE techniques. Recently, introduced T1 mapping-based quantification can provide the volume of extracellular space suggestive of the degree of diffuse tissue fibrosis or inflammation. Even without gadolinium contrast, native T1 values can provide quantitative information on myocardial tissue status. Here, we review current evidence for T1 mapping-based risk stratification and prognostication for various cardiac diseases that can lead to heart failure or lethal arrhythmic events.

Revised: July 7, 2017

Accepted: July 12, 2017

Corresponding author

Eui-Young Choi, MD, PhD

Division of Cardiology, Heart Center,

Gangnam Severance Hospital,

Yonsei University College of Medicine,

211 Eonju-ro, Gangnam-gu,

Seoul 06273, Korea

Tel: 82-2-2019-3310

Fax: 82-2-3463-3882

E-mail: choi0928@yuhs.ac
Key words Cardiac magnetic resonance imaging · T1 mapping · Prognosis.

\section{INTRODUCTION}

Several studies have explored tissue validation of T1 mapping [1-3]. Currently, T1 relaxation time and calculated extracellular volume fraction (ECV) are accepted as reliable markers of the degree of diffuse interstitial fibrosis [4]. T1 mapping data are used in various clinical studies as early detectors of disease or imaging-based biomarkers guiding specific therapies. However, native $\mathrm{T} 1$, post-T1 and ECV values vary by equipment manufacturer and according to the magnetic field strength and mapping sequence used $[5,6]$ So, compared to left ventricular (LV) mass, volume and late gadolinium enhancement (LGE) imaging data, multi-vender-based multicenter T1 mapping studies have

(a) This is an Open Access article distributed under the terms of the Creative Commons Attribution Non-Commercial License (http://creativecommons.org/licenses/bync/4.0) which permits unrestricted non-commercial use, distribution, and reproduction in any medium, provided the original work is properly cited. several limitations. Thus, standardization of T1 mapping is important. In this review, we focus on the prognostic role of T1 mapping for various clinical disease entities.

\section{BASIC CONCEPTS AND TECHNICAL ASPECTS}

The general principle of $\mathrm{T} 1$ mapping is to acquire multiple images with different $\mathrm{T} 1$ weights and to fit the signal intensities of the images to the equation for T1 relaxation. T1-weighted images are acquired at different times after inversion of the magnetization or at different times after a saturation pulse. Pixel intensities in the finally reconstructed $\mathrm{T} 1$ images correspond to the fitted $\mathrm{T} 1$ values [7]. T1 mapping has an advantage in that it is a pixel-wise map and is objective; one disadvantage is that partial volume effects can lead to artifacts, but motion correction and 
co-registration techniques are helping to minimize these effects. T1 mapping provides an intrinsic signal from both the myocytes and the interstitial tissue. Native T1 is prolonged with fibrosis, edema and amyloid and is reduced in lipid accumulation (Anderson-Fabry disease), cardiac siderosis, and hemorrhage in acute infarction (Fig. 1) [7]. However, when using ECV and native T1, not only fibrosis but also combined myocardial inflammation should be considered [8]. Currently, most popular T1 pulse sequences are modified look-locker inversion recovery (MOLLI), shortened MOLLI (shMOLLI) and saturation recovery single single-shot acquisition (SASHA) (Fig. 2) [7]. As previously mentioned, standardization of results across different instruments and sequences is important for interpretation of data across various studies and centers. Currently, work is underway to standardize T1 mapping using a specialized phantom [9]. This effort can improve the precision and accuracy of the T1 mapping technique and can be used in multi-center studies. Another approach is to standardize $\mathrm{T} 1$ values by calculating a $\mathrm{Z}$ score, which is a standard score. In one study, converting T1 values to $\mathrm{Z}$ scores significantly improved the agreement between
SASHA and shMOLLI techniques, particularly for post-contrast $\mathrm{T} 1$ and ECV [10]. In addition, the current consensus statement recommends that each center derive their own normal values [11].

Usage of post-T1 requires correction by blood $\mathrm{T} 1$ to reduce time-dependent differences and effects of blood flow stasis [12]. ECV is calculated using gadolinium distribution mechanics after full saturation and steady status. Blood extracellular space should be considered using blood hematocrit (Hct) concentration to estimate intracellular volume space. As such, 1-Hct can be used as a proxy for the extracellular volume status of blood. Change in 1/ $\mathrm{T} 1$ in blood and tissue is expressed as change in longitudinal relaxation $(\Delta \mathrm{R} 1)$ for blood $(\Delta \mathrm{R} 1$ blood $)$ and $\Delta \mathrm{R} 1$ for tissue ( $\triangle \mathrm{R} 1$ tissue), then ECV can be calculated as $(1-\mathrm{Hct}) \times \Delta \mathrm{R} 1$ tissue/ $\Delta \mathrm{R} 1$ blood [11]. To make it more convenient in practice, a synthetic ECV method has recently been introduced [13]. The main mechanism of this method is pixel T1-based calculation of ECV without Hct concentration. The R1 of blood was found to have a linear relationship with blood Hct. The regression equations were: Synthetic HctMOLLI=[866.0 • (1/T1blood)]- 0.1232; Synthetic HctShMOLLI=[727.1 $\cdot(1 /$ T1blood $)]-0.0675$ [13].

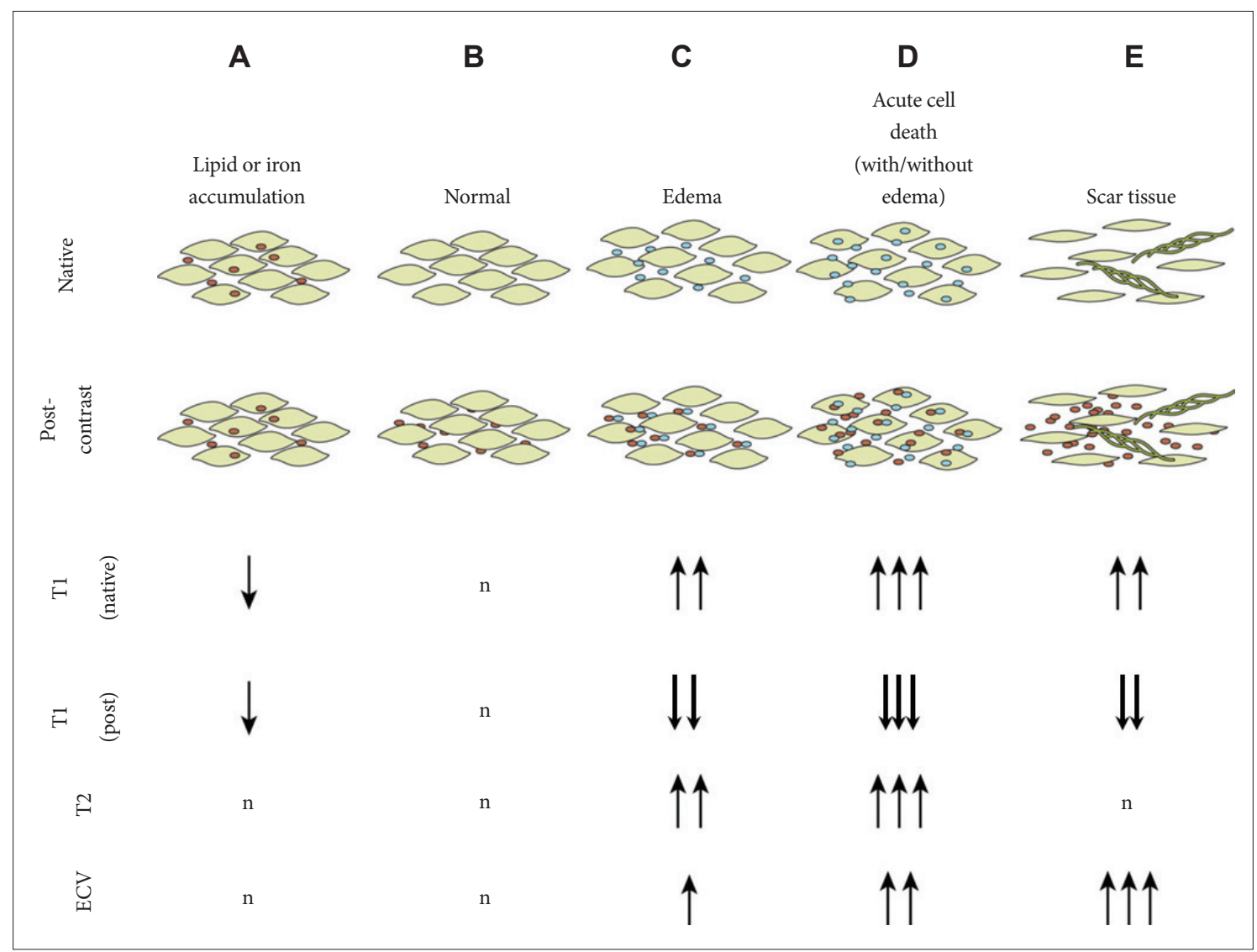

Fig. 1. A schematic representation of tissue changes in T1 measurements. (A) Lipid or iron accumulation (red dots) reduces native T1 values, irrespective of the T1 accuracy or T2 sensitivity of a given sequence. (B) Normal, minimal or no accumulation. (C and D) Accumulation of water (blue dots) leads to an increase in native T1, which is more pronounced in T2-sensitive sequences. (E) Similarly, scar tissue leads to increase in native T1. Conversely, accumulation of gadolinium contrast agents (GCAs) in extracellular space (green dots) leads to reduced post-contrast T1 (Adapted from Puntmann et al. Circ Res 2016;119:277-299. [4]). ECV: extracellular volume fraction. 


\section{RISK STRATIFICATION IN THE GENERAL POPULATION}

\section{Normal values of native T1, post-T1 and ECV}

With MOLLI sequencing, which is the most popular T1 mapping sequence, normal myocardial native $\mathrm{T} 1$ ranges from 950 to $982 \mathrm{~ms}$ and thereby ECV is 25.0 to $26.9 \%$ in a $1.5 \mathrm{~T}$ magnetic field $[5,6,14,15]$. In a $3 \mathrm{~T}$ magnetic field, native $\mathrm{T} 1$ is somewhat prolonged to 1052 to $1159 \mathrm{~ms}[6,16]$. Although reference values have been published in several studies, the current consensus statement recommends that each center should derive normal values for their specific center [11] Table 1 shows an overview of studies reporting normative ranges for T1-mapping indices.
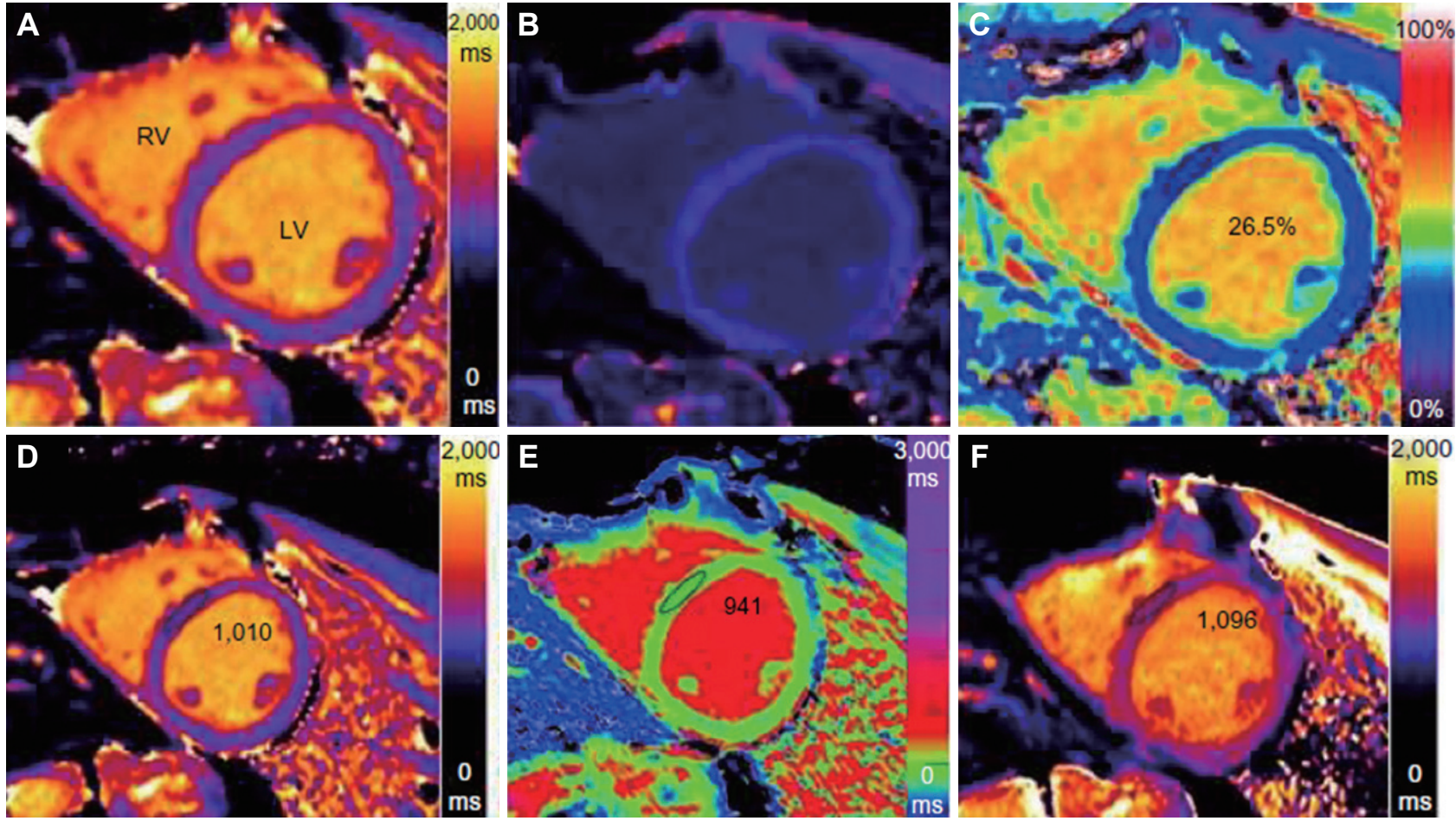

Fig. 2. Representative images of T1 mapping. (A) Native T1 MOLLI map (myocardial T1 $1010 \mathrm{~ms}$ ). (B) Post-contrast T1 MOLLI map (myocardial T1 $615 \mathrm{~ms}$ ). (C) ECV map (ECV=26.5\%). (D) Native T1 map by MOLLI. (E) ShMOLLI and (F) SASHA (Adapted from Abdel-Gadir et al. Res Rep Clin Cardiol 2014;5:339. [69]). MOLLI: modified look-locker inversion recovery, ECV: extracellular volume fraction, ShMOLLI: shortened MOLLI, SASHA: saturation recovery single-shot acquisition, RV: right ventricular, LV: left ventricular.

Table 1. Overview of studies reporting normative ranges for T1 mapping indices

\begin{tabular}{|c|c|c|c|c|c|c|c|}
\hline \multirow{2}{*}{$\begin{array}{c}\text { Study } \\
\text { (n=participants) }\end{array}$} & \multirow{2}{*}{ Pulse sequence } & \multirow{2}{*}{ GCAs (dose and type) } & \multirow{2}{*}{ T1 index } & \multicolumn{2}{|c|}{$1.5 \mathrm{~T}$} & \multicolumn{2}{|c|}{$3.0 \mathrm{~T}$} \\
\hline & & & & Myocardium & Blood & Myocardium & Blood \\
\hline $\begin{array}{l}\text { Messroghli et al. [5] } \\
\quad(n=43)\end{array}$ & $\begin{array}{l}\text { MOLLI 3(3)3(3)5 } \\
\quad(\text { FA 50) }\end{array}$ & $\begin{array}{l}0.15 \mathrm{mmol} / \mathrm{kg} \text { gadopentetate } \\
\text { dimeglumine }\end{array}$ & Native T1, ms & $982 \pm 46$ & & & \\
\hline $\begin{array}{l}\text { Piechnik et al. [14] } \\
\qquad(\mathrm{n}=342)\end{array}$ & $\begin{array}{l}\text { MOLLI 5(1)1(1)1 } \\
\quad(\text { FA 35 })\end{array}$ & $\begin{array}{l}0.15 \mathrm{mmol} / \mathrm{kg} \text { gadopentetate } \\
\text { dimeglumine }\end{array}$ & Native T1, ms & $962 \pm 25$ & $1535 \pm 76$ & & \\
\hline $\begin{array}{l}\text { Dabir et al. [6] } \\
(n=102)\end{array}$ & $\begin{array}{l}\text { MOLLI 3(3)3(3)5 } \\
\quad(\text { FA 50 })\end{array}$ & $0.1-0.2 \mathrm{mmol} / \mathrm{kg}$ gadobutrol & $\begin{array}{l}\text { Native T1, ms } \\
\text { ECV, \% }\end{array}$ & $\begin{array}{c}950 \pm 21 \\
25 \pm 4\end{array}$ & $1551 \pm 115$ & $\begin{array}{c}1052 \pm 23 \\
26 \pm 4\end{array}$ & $1736 \pm 139$ \\
\hline $\begin{array}{l}\text { Liu et al. [15] } \\
\qquad(\mathrm{n}=1231)\end{array}$ & $\begin{array}{l}\text { MOLLI 3(3)3(3)5 } \\
\quad(\text { FA 35 })\end{array}$ & $\begin{array}{l}0.15 \mathrm{mmol} / \mathrm{kg} \text { gadopentetate } \\
\text { dimeglumine }\end{array}$ & $\begin{array}{l}\text { Native T1, ms } \\
\text { ECV, \% }\end{array}$ & $\begin{array}{l}977 \pm 42 \\
26.9 \pm 2.8\end{array}$ & & & \\
\hline $\begin{array}{l}\text { von Knobelsdorff- } \\
\text { Brenkenhoff } \\
\text { et al. [16] }(n=60)\end{array}$ & $\begin{array}{l}\text { MOLLI 3(3)3(3)5 } \\
\quad(\text { FA 35 })\end{array}$ & $0.2 \mathrm{mmol} / \mathrm{kg}$ gadobutrol & Native $\mathrm{T} 1, \mathrm{~ms}$ & & & $1159 \pm 73$ & \\
\hline
\end{tabular}

The number of participants per group and mean values (mean \pm SD) are reported for the type of sequence, T1 index, field strength and T1mapping indices. Post-contrast T1 measurements were typically obtained $>15$ minutes after contrast administration (Adapted from Puntmann et al. Circ Res 2016;119:277-299. [4]). ECV: extracellular volume fraction, FA: flip angle, GCA: gadolinium contrast agents, MOLLI: modified look-locker inversion recovery. 


\section{Relation to sex, age and cardiovascular risk factors}

There are a few general population-based studies in which the relationships between $\mathrm{T} 1$ value and conventional cardiac risk factors such as gender, age, diabetes, hypertension or dyslipidemia are reported $[15,17]$. The recent Multi-Ethnic Study of Atherosclerosis (MESA) showed post-T1 was correlated with age and risk factors [15]. In that study, women had a significantly greater partition coefficient, ECV and native $\mathrm{T} 1$ than men, as well as lower post-contrast $\mathrm{T} 1$ values (all $\mathrm{p}<0.05$ ). In general, linear regression analyses demonstrated that a greater partition coefficient, native $\mathrm{T} 1$ values and $\mathrm{ECV}$ were associated with older age in men (multivariate regression coefficients $=0.01 ; 5.9 \mathrm{~ms}$; and $1.04 \%$ per 10 year change; all $\mathrm{p}<0.05)$. ECV was also significantly associated with age in women after multivariate adjustments [15]. In another MESA study, 25-minute post-gadolinium T1 time showed more statistically significant associations with cardiovascular disease risk scores (10/14 scores, 71\%) com- pared to other cardiac magnetic resonance (CMR) imaging indices (e.g., native T1; 7/14 scores, 50\%) and the partition coefficient $(7 / 14,50 \%)$ in men [17]. Risk scores, particularly the new 2013 American Heart Association/AtheroSclerotic Cardiovascular Disease risk score, did not correlate with any CMR fibrosis index [17]. Bulluck et al. [18] recently reported that myocardial native $\mathrm{T} 1$ values correlated with blood $\mathrm{T} 1$ and heart rate. However, even after adjustment for heart rate and blood $\mathrm{T} 1$, females had higher native $\mathrm{T} 1$ values, so gender-specific T1 values should be established at each center. Association with age is controversial but, in women, age correlated with native T1 values in that study. Due to short-term follow-up after acquisition of T1 mapping, there is currently no prognostic role for T1 mapping in the general population.
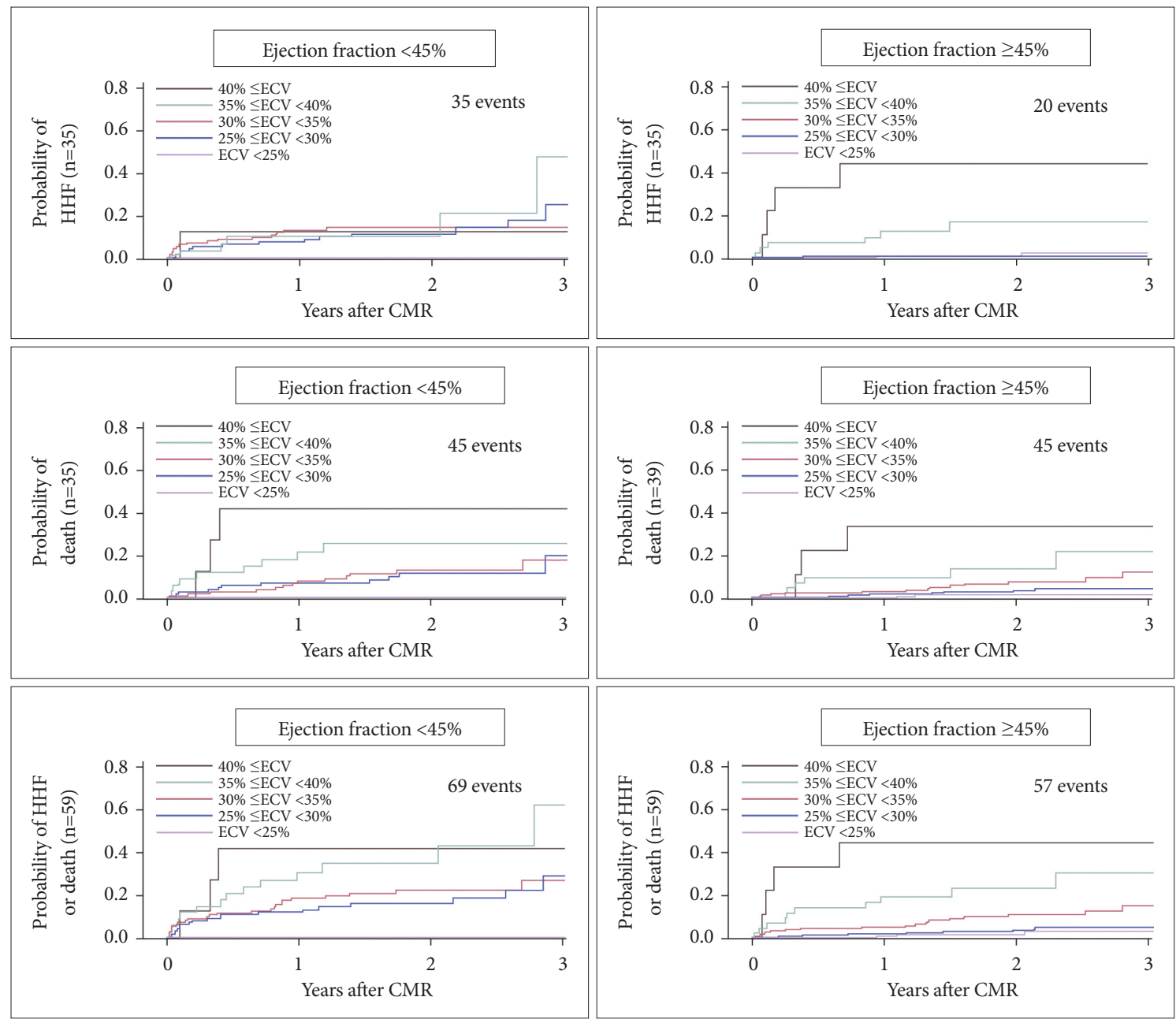

Fig. 3. ECV was significantly associated with adverse outcomes in univariate Cox regression models $(p<0.05$ for all), whether EF was reduced $(<45 \%)$ or preserved $(E F \geq 45 \%)$. Despite the decreased statistical power occurring with subgroup analysis, the basis for the statistically significant interactions between ECV and EF was evident qualitatively. Associations between ECV measures at the lower end of the ECV spectrum and events appeared strengthened when EF was reduced (Adapted from Schelbert et al. J Am Heart Assoc 2015;4:e002613. [20]). ECV: extracellular volume fraction, EF: ejection fraction, CMR: cardiac magnetic resonance, HHF: hospitalization for heart failure. 


\section{Heart failure with preserved ejection fraction (HFpEF) or reduced EF}

An early study showed that CMR-based post-contrast T1 time [hazard ratio (HR), 0.99; 95\% confidence interval (CI): 0.980.99; $\mathrm{p}=0.046]$, left atrial area (HR, 1.08; 95\% CI: 1.03-1.13; $\mathrm{p}<$ 0.01 ) and pulmonary vascular resistance (HR, 1.01 ; $95 \%$ CI: $1.00-$ 1.01; $\mathrm{p}=0.03$ ) were significantly associated with cardiac events in patients with heart failure (HF) with preserved ejection fraction (HFpEF) [19]. Patients with post-T1 times below the median $(<388.3 \mathrm{~ms})$ were at greater risk of cardiac events than the rest of the group $(\mathrm{p}<0.01)$. The extracellular matrix from LV biopsies as quantified using TissueFAXS technology correlated with $\mathrm{T} 1$ time. Thus, post-contrast $\mathrm{T} 1$ time was associated with prognosis in HFpEF, suggesting post-contrast $\mathrm{T} 1$ as a possible biomarker for HFpEF [19]. In another study, Schelbert et al. [20] reported myocardial fibrosis with ECV measures in 1172 consecutive patients without amyloidosis, hypertrophic or stress cardiomyopathy and assessed associations with outcomes using Cox regression (Fig. 3). Adjusting for age, gender, renal function, myocardial infarction size, ejection fraction (EF), hospitalization status, and HF stage, higher ECV was associated with hospitalization for HF (HR, 1.77; 95\% CI: 1.32-2.36 for every $5 \%$ increase in ECV), death (HR, 1.87; 95\% CI: 1.45-2.40) or both (HR, 1.85; 95\% CI: 1.50-2.27). ECV improved classification of persons at risk and improved model discrimination for outcomes. This suggested that myocardial fibrosis measured by ECV was associated with hospitalization for HF, death, or both. Myocardial fibrosis may represent a principal phenotype of cardiac vulnerability that improves risk stratification. It has been suggested that myocardial fibrosis can be reversed, and cells and enzymes regulating collagen could be potential therapeutic targets [20]. However a more recent prospective study showed that MOLLI-ECV in HFpEF accurately reflected histological ECV and correlated with markers of disease severity; ECV $\geq$ $28.9 \%$ (median) was associated with shorter event-free survival (log-rank, $\mathrm{p}=0.028$ ), but not after adjustment for important clinical and invasive hemodynamic parameters (Table 2) [21]. The problems to be solved are that conventional echo-based diastolic functional parameters such as E/e' were not included in the multivariate analysis and many patients were excluded due to previous pacemaker/implantable cardioverter-defibrillator (ICD) implantation, estimated glomerular filtration rate $(e G F R)<30$ $\mathrm{mL} / \mathrm{min}$, claustrophobia, immobility and premature discontinuation of CMR scanning. Even in the excluded patients, echo-derived $\mathrm{E} / \mathrm{e}$ and blood $\mathrm{N}$-terminal pro-B-type natriuretic peptide (NT-proBNP) measurement are possible. Thus, in clinical practice, prognostication in HFpEF patients needs further improvement for patient convenience.

\section{Acute myocardial infarction and ischemic cardiomyopathy}

In acute myocardial infarction patients, increased remote ECV, higher ECV in infarct and higher remote ECV were related to adverse remodeling, which suggests quantitative ECV can provide insight into the pathophysiology of LV remodeling and prognosis [22]. In ST elevation myocardial infarction patients, higher core native $\mathrm{T} 1$ was related to all-cause death or first hospitalization for HF post-discharge [23]. Although a sub-study of the Surgical Treatment for Ischemic Heart Failure trial failed to demonstrate the utility of pre-procedural viability assessment with dobutamine stress echocardiography or single-photon-emission computed tomography to guide revascularization in patients with ischemic cardiomyopathy [24,25], other studies support the identification of myocardial fibrosis as carrying important prognostic information [26]. Chen et al. [27] reported that native T1 was an independent predictor of ventricular arrhythmia in ischemic cardiomyopathy. The ongoing development of new techniques, particularly $\mathrm{T} 1$ mapping of the $\mathrm{ECV}$, holds promise for the future as early studies suggested its complementary prognostic value and its avoiding contrast administration [28]. However, whether T1 mapping-guided revascularization imaging can improve disease prognosis has not been studied. A summary of T1 mapping-based prognostication studies in ischemic heart disease, cardiomyopathies and valvular heart diseases are de-

Table 2. Summary of prognostic value of T1 mapping in heart failure with preserved ejection fraction

\begin{tabular}{|c|c|c|c|c|c|c|}
\hline Study & Parameter & End-point & Univariate & Multivariate & Co-variates & Exclusion (\%) \\
\hline $\begin{array}{l}\text { Schelbert et al. [20] } \\
\qquad(\mathrm{n}=1172)\end{array}$ & ECV & $\begin{array}{l}\text { Hospitalization for heart } \\
\text { failure/death }\end{array}$ & $\mathrm{p}<0.001$ & $\mathrm{p}<0.01$ & $\begin{array}{l}\text { Age, eGFR, myocardial infarction } \\
\text { size, gender, heart failure stage }\end{array}$ & $1765 / 597(34)$ \\
\hline $\begin{array}{l}\text { Mascherbauer } \\
\text { et al. [19] }(n=100)\end{array}$ & Post-T1 & $\begin{array}{l}\text { Hospitalization for heart } \\
\text { failure or death from } \\
\text { cardiovascular causes }\end{array}$ & $\mathrm{p}=0.01$ & $\mathrm{p}=0.046$ & $\begin{array}{l}\text { Left atrial area } \\
\text { Pulmonary vascular resistance } \\
\text { NT-proBNP }\end{array}$ & Not mentioned \\
\hline $\begin{array}{l}\text { Duca et al. [21] } \\
\qquad(\mathrm{n}=117)\end{array}$ & $\mathrm{ECV}$ & $\begin{array}{l}\text { Hospitalization for heart } \\
\text { failure/death from } \\
\text { cardiovascular causes }\end{array}$ & $\mathrm{p}=0.038$ & $\mathrm{p}=0.978$ & $\begin{array}{l}\text { eGFR } \\
\text { NT-proBNP } \\
\text { Right ventricular end-diastolic } \\
\text { volume, pulmonary vascular } \\
\text { resistance }\end{array}$ & $80 / 197(41)$ \\
\hline
\end{tabular}

ECV: extracellular volume fraction, eGFR: estimated glomerular filtration rate, NT-proBNP: N-terminal pro-B-type natriuretic peptide 
Prognostication with T1 Mapping

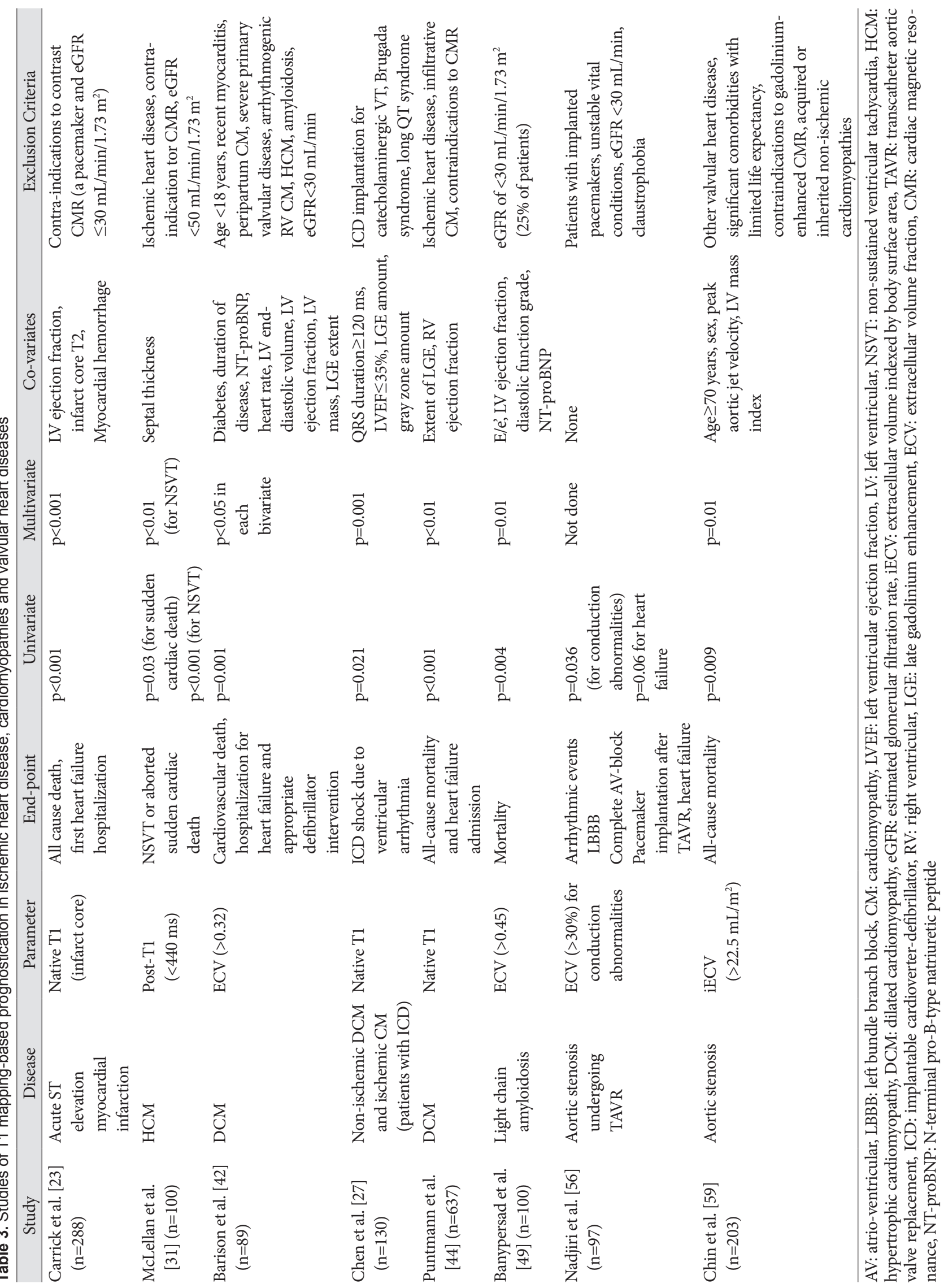


scribed in Table 3.

\section{Prognostic value for various non-ischemic cardiomyopathies}

\section{Hypertrophic cardiomyopathy (HCM)}

Many previous studies have shown that the amount of LGE was related to future cardiovascular events, especially sudden death due to ventricular arrhythmic events $[29,30]$. The amount of LGE, especially more than $15 \%$ of the LV mass, can be an indication that ICD implantation might be able to prevent such an event [29]. However, whether a T1 map-based ECV provides additive prognostic value for the LGE amount is not known. Because about two thirds of hypertrophic cardiomyopathy (HCM) patients have LGE, the role of T1 mapping for prediction of prognosis may be focused on the remaining 30\% non-LGE patients or remote myocardium in cases with LGE. In addition, whether the average ECV or T1 value of the whole myocardium is better than the LGE amount for prognostication is not known. Only one study showed that the average of whole LV post-contrast ventricular T1 relaxation time was significantly reduced in patients with non-sustained ventricular tachycardia and patients with aborted sudden cardiac death [31]. Although the value for prognostication is limited, native T1 data can be helpful for discriminating infiltrative cardiomyopathies, such as Fabry cardiomyopathy or hemochromatosis from HCM in patients with thickened myocardium [32-35]. Compared to other disease entities, the native T1 value is uniquely decreased in Fabry cardiomyopathy [33] and hemochromatosis [35]. Native T1 data were shown to be independent discriminators between HCM and hypertension or an athlete's heart, over and above ECV, LV wall thickness and indexed LV mass [36,37]. Native T1 was also useful for separating positive genotype but not negative phenotype subjects from controls [36]. In HCM, contrast-enhanced CMR with T1 mapping can non-invasively evaluate regional and diffuse patterns of myocardial fibrosis. These patterns of fibrosis occur independently of each other and exhibit distinct clinical associations. HCM patients with recognized genetic mutations have significantly more regional but less diffuse myocardial fibrosis compared to those without [38].

\section{Dilated cardiomyopathy (DCM)}

The role of T1 mapping is promising for non-ischemic dilated cardiomyopathy (DCM) because a typical mid-wall LGE pattern is not as prevalent as seen in HCM. Generally 44\% (21 to $70 \%$ ) of non-ischemic DCM patients have been shown to have LGE [39], so theoretically, ECV might be useful in DCM patients without LGE. In addition, in all DCM patients, remote nonLGE area ECV could provide significant additive information for risk stratification and prognostication. For instance, in one study, a post-T1 value $>450 \mathrm{~ms}$ was an independent predictor of $\mathrm{LV}$ reverse remodeling at follow-up (LV systolic volume index $\Delta=24.6 \mathrm{~mL} / \mathrm{m}^{2}$ standard error $14.6 \mathrm{~mL} / \mathrm{m}^{2}, \mathrm{p}=0.0480$ ) in patients despite the presence of LGE, even after adjusting for their Seattle Heart Failure Score [40]. While DCM patients with focal LGE demonstrated greater adverse LV remodeling than those without focal fibrosis, diffuse fibrosis independently predicted LV reverse remodeling in DCM patients despite the presence of focal fibrosis [40]. Our group also observed that post-contrast $\mathrm{T} 1$ is closely related to LV remodeling, diastolic function and neurohormonal activation, measured by NT-proBNP level [41]. Barison et al. [42] showed myocardial ECV was an independent prognostic predictor beyond all other conventional clinical, electrocardiographic and echocardiographic parameters. Also, Chen et al. [27] demonstrated that quantitative myocardial tissue assessment using T1 mapping was an independent predictor of ventricular arrhythmia in both ischemic and non-ischemic cardiomyopathies. Regarding cardiac resynchronization therapy response, focal scar burden detected by LGE-CMR was associated with a poor response to cardiac resynchronization therapy. A previous study showed that diffuse interstitial fibrosis assessment by $\mathrm{T} 1$ mapping, however, was not independently predictive of cardiac resynchronization therapy response [43]. Recently, an important prospective multicenter longitudinal study in 637 consecutive patients with DCM \{mean age 50 years [interquartile range (IQR) 37-76 years]; 395 males [62\%]\} underwent CMR with T1 mapping and LGE at $1.5 \mathrm{~T}$ and $3.0 \mathrm{~T}$ field strengths. During a median follow-up period of 22 months (IQR 19-25 months), a total of 28 deaths (22 cardiac) and 68 composite HF events were observed. T1 mapping indices (native T1 and ECV), as well as the presence and extent of LGE, were predictive of all-cause mortality and HF endpoint ( $p<0.001$ for all). Multivariate analyses showed native T1 was the sole independent predictor of all-cause and HF composite endpoints (HR, 1.1; 95\% CI: 1.06-1.15; HR, 1.1; 95\% CI: 1.05-1.1; $\mathrm{p}<0.001$ for both), followed by the models including the extent of LGE and right ventricular EF, respectively (Fig. 4) [44].

\section{Cardiac amyloidosis and sarcoidosis}

Although native T1 and ECV data are helpful for early detection of cardiac involvement in systemic amyloidosis or suspected cardiac amyloidosis [45-47], the prognostic value of T1 mapping is rarely reported. T1 mapping can also provide information about disease severity and serve as a monitoring tool for chemotherapy in amyloid light-chain amyloidosis [48]. Banypersad et al. [49] showed ECV was independently predictive of mortality (HR, 4.41; 95\% CI: 1.35-14.4) after adjusting for E/e', EF, diastolic dysfunction grade and NT-proBNP, but not with native T1 data in light chain amyloidosis. Greulich et al. [50] reported that sarcoid patients had a higher median native T1 (994 vs. 960 ms; 
$\mathrm{p}<0.001$ ), lower post-T1 (491 vs. $526 \mathrm{~ms} ; \mathrm{p}=0.001$ ), expanded extracellular volume ( 28 vs. $25 \%$; $\mathrm{p}=0.001$ ), and higher $\mathrm{T} 2$ values (52 vs. 49 ms; $\mathrm{p}<0.001$ ) compared with controls. Thus, patients with sarcoidosis demonstrated higher T1 values, extracellular volume, and T2 values compared to healthy controls, with the most significant differences seen in native $\mathrm{T} 1$ and $\mathrm{T} 2$ data.

\section{Tachycardia-induced cardiomyopathy}

A recent study showed that compared with controls, atrial tachycardia with low EF patients had reduced global LV corrected post-T1 times ( $442 \pm 53$ vs. $529 \pm 61 \mathrm{~ms} ; \mathrm{p}<0.05$ ), consistent with diffuse fibrosis. Tachycardia-mediated cardiomyopathy patients exhibited differences in LV structure and function including diffuse fibrosis long after arrhythmia cure, indicating that recovery was incomplete [51].

\section{Acute and chronic myocarditis}

Limited data are available regarding the degree of normalization of CMR parameters during the course of the disease and the time window during which quantitative CMR should be most reasonably implemented for diagnostic work-up. Regarding this question, Luetkens et al. [52] reported that there was a significant and consistent decrease in all inflammatory CMR parameters over the course of the disease $(\mathrm{p}<0.01$ for all parameters). Myocardial T1 and T2 relaxation times-indicative of myocardial edema-were the only single parameters showing significant differences between myocarditis patients and control subjects at the 5.5 \pm 1.3 -week follow-up (native T1: 986.5 \pm 44.4 vs. $965.1 \pm$
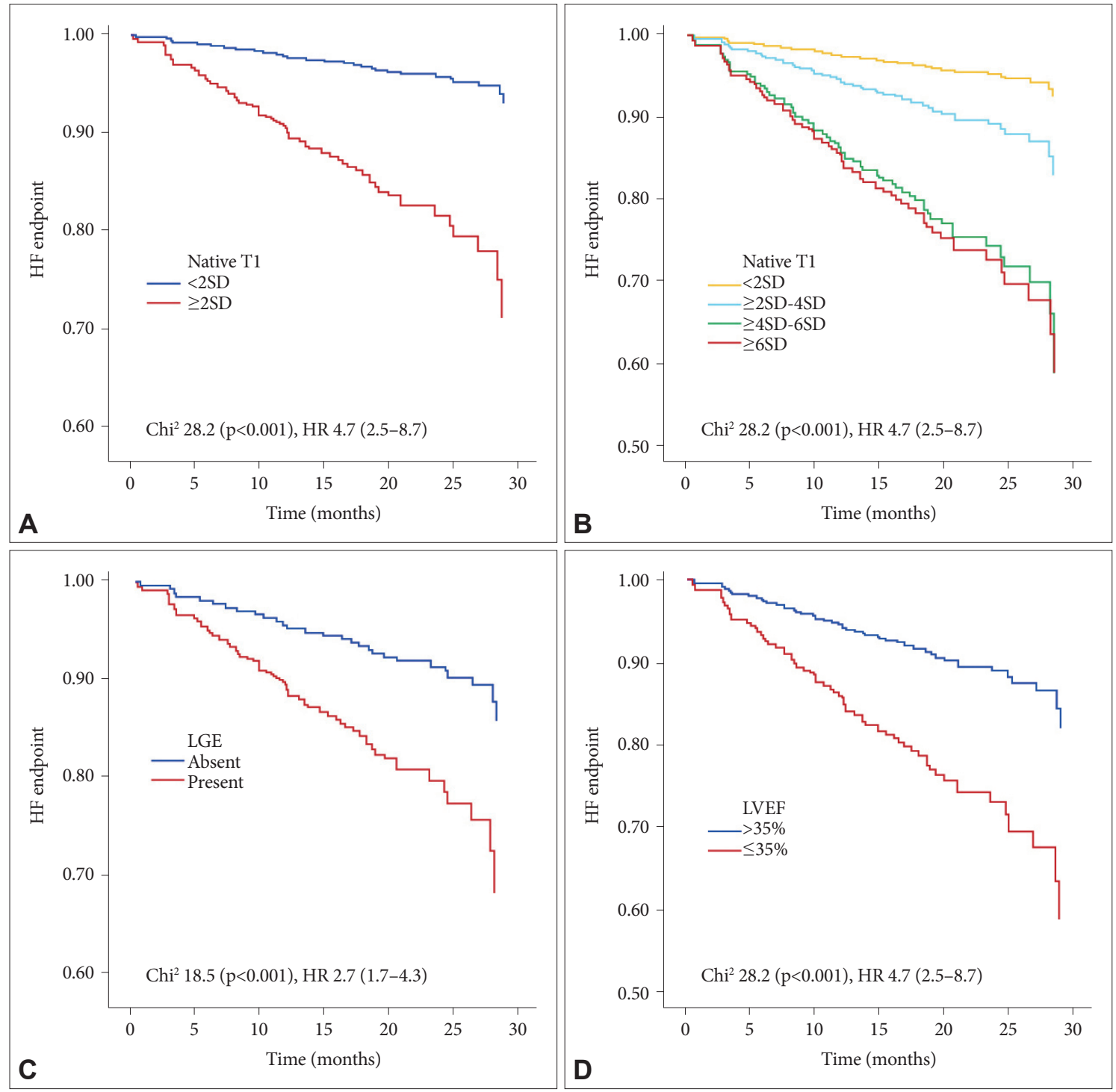

Fig. 4. (A) Native T1 [normal vs. abnormal myocardium, based on $>2$ standard deviations (SD) above the mean of the normal reference range]. (B) Native T1 ranked by $2 n$-times SD (ranks of SD: $<2, \geq 2$ to $4, \geq 4$ to $6, \geq 6$ ), (C) LGE present vs. absent and (D) LVEF $<35 \%$ (Adapted from Puntmann et al. JACC Cardiovasc Imaging 2016;9:40-50. [44]). HR: hazard ratio, LGE: late gadolinium enhancement, LVEF: left ventricular ejection fraction, HF: heart failure. 
$28.1 \mathrm{~ms}, \mathrm{p}=0.022$; T2: $55.5 \pm 3.2$ vs. $52.6 \pm 2.6 \mathrm{~ms}, \mathrm{p}=0.001$ ). They concluded that myocardial native $\mathrm{T} 1$ and $\mathrm{T} 2$ relaxation times were the only active inflammation/edema parameters that could discriminate between myocarditis patients and control subjects even during the convalescent stage of the disease. von Knobelsdorff-Brenkenhoff et al. [53] reported that although both T2 and T1 mapping reliably detected acute myocarditis, only T2 mapping discriminated between acute and healed stages, underlining the incremental value of $\mathrm{T} 2$ mapping.

\section{Prognostic value in valvular heart diseases}

\section{Aortic stenosis}

As patient numbers increase, the role of prognostication becomes important, especially in fragile patients. Current issues include peri-surgical aortic valve replacement or peri-transcatheter aortic valve replacement (TAVR) risk stratification. From this point of view, LGE presence and amount provides useful prognostic information [54,55], but the additive prognostic value of T1 mapping remains unclear. Some previous reports revealed that ECV or native $\mathrm{T} 1$ values could be helpful for the prediction of arrhythmic events or complete atrio-ventricular (AV)-block after the TAVR procedure [56]. For example, patients with post-TAVR conduction abnormality (left bundle branch block, AV-block or pacemaker implantation) had statistically significantly lower ECV values compared to those without an event. Patients with an event had a mean ECV of $28.1 \pm 3.16 \%$; patients without an event had a mean ECV of $29.8 \pm 4.53 \%$ (HR, 0.56; 95\% CI: 0.32-0.96, $\mathrm{p}=0.036$ ). In this study, elevated myocardial ECV was a trending predictor of HF; CMR may be helpful in identifying patients at high risk for post-TAVR cardiac decompensation benefitting from intensified post-interventional surveillance [56]. So CMR-T1 mapping can guide selection of TAVR-valve type, which results in less conduction system compromise in cases with a high risk of conduction disturbance. In addition, elderly persons and those with chronic kidney disease are very common in cases with severe aortic stenosis, so native $\mathrm{T} 1$ without contrast could provide helpful information without the use of gadolinium contrast media [57,58]. Chin et al. [59] used total extracellular volume indexed by body surface area (iECV) was together with LGE to categorize patients with normal myocardium (iECV $<22.5 \mathrm{~mL} / \mathrm{m}^{2} ; 51 \%$ of patients), extracellular expansion (iECV $\geq 22.5 \mathrm{~mL} / \mathrm{m}^{2} ; 22 \%$ ), and replacement fibrosis (presence of mid-wall LGE, 27\%). In that study, categorization by ECV was of prognostic value with stepwise increases in unadjusted all-cause mortality ( 8 deaths/1000 patient-years vs. 36 deaths $/ 1000$ patient-years vs. 71 deaths $/ 1,000$ patientyears, respectively; $\mathrm{p}=0.009$ ).

\section{Mitral regurgitation and aortic regurgitation}

A few studies have shown that the presence of preoperative myocardial fibrosis assessed with LGE-CMR was an independent predictor of increased adverse clinical outcomes in patients with chronic degenerative mitral regurgitation $[60,61]$. Chaikriangkrai et al. [61] reported that preoperative LGE may be of clinical utility for the prediction of outcomes during perimitral valve repair. Myocardial ECV was increased ( $32 \pm 7 \%$ vs. $25 \pm 2 \%, \mathrm{p}<0.01)$ in severe mitral regurgitation patients compared to healthy controls. ECV was associated with increased $\mathrm{LV}$ end-systolic volume index $(\mathrm{r}=0.62, \mathrm{p}<0.01)$, left atrial volume index $(r=0.41, p<0.05)$, lower LV EF $(r=-0.60, p<0.01)$, longitudinal function (mitral annular plane systolic excursion, $\mathrm{r}=-$ $0.46, \mathrm{p}<0.01)$ and peak VO2 $\max (\mathrm{r}=-0.51, \mathrm{p}<0.05)$. A multivariate regression model showed LV end-systolic volume index and left atrial volume index were independent predictors of ECV $\left(r^{2}=0.42, p<0.01\right)[58,62]$. A recent study by Bui et al. [63] reported that patients with mitral valve prolapse with complex ventricular arrhythmia (ComVA) had significantly shorter postT1 times when compared with patients with mitral valve prolapse without ComVA [324 (IQR 296-348) vs. 354 (IQR 327-376) $\mathrm{ms} ; \mathrm{p}=0.03$ ] and only $5 / 14(36 \%)$ had evidence of papillary muscle LGE. Mitral valve prolapse may be associated with diffuse LV myocardial fibrosis as suggested by reduced post-T1 times. They concluded that diffuse interstitial derangement was linked to subclinical systolic dysfunction, and may have contributed to ComVA in mitral valve prolapse-related mitral regurgitation, even in the absence of focal fibrosis. Prediction of LV function after mitral valve or aortic valve surgery in cases with severely depressed LV function is challenging. Due to prediction uncertainty for LV function recovery, several parameters are potential predictors [64]. The basic concept of reversibility prediction is based on degree of myocardial fibrosis, especially diffuse interstitial fibrosis. At this point, ECV or native T1 values are helpful indexes. However, few studies have examined this issue. LGE positive signal in CMR is a potential predictor of persistent cardiac failure after aortic valve replacement for patients with severe chronic aortic regurgitation and an extremely dilated LV chamber. This has an intimate relationship with malignant arrhythmia and sudden death, which makes this a valuable technique in preoperative evaluation and risk stratification $[60,65]$. However, no T1 mapping-based prognostication studies in severe aortic regurgitation patients have yet been conducted.

\section{Perspectives and challenges}

Because there is already a great deal of evidence for LGE prognostication, T1 mapping-based parameters should provide additive information beyond that provided by LGE. However, quantification of LGE amount for various cardiac diseases, especially in cardiomyopathies, shows measurement variability 
[66,67]. In contrast, measurement of average ECV or native T1 in whole LV myocardium is more convenient for researchers. Therefore, a head-to-head comparison asking which parameter (amount of LGE and average T1) is better for prognostication is needed, because there is an increase in the number of HF patients, an aging population and an increasing prevalence of concomitant kidney disease. Although a far improvement for avoiding systemic nephrogenic fibrosis, gadolinium usage is still limited in patients with glomerular filtration rates less than $45 \mathrm{~mL} / \mathrm{min} / \mathrm{m}^{2}$. In those cases, native T1-based imaging would provide safe and reliable information about myocardial tissue characteristics [68]. After establishment of a standardization protocol for image acquisition and motion correction algorithm, it could be used in various centers and multi-nations around the world. Most importantly, the protocol could be used as a sensitive and reliable tool to demonstrate the effects of new treatments.

\section{CONCLUSION}

In regard to risk stratification and prognostication for cardiovascular events including sudden death, current evidence is mainly focused on non-ischemic cardiomyopathy such as HCM and DCM. However, a growing number of studies have demonstrated the role of $\mathrm{T} 1$ in risk stratification in various disease entities, including ischemic and valvular heart disease.

\section{Conflicts of Interest}

The authors declare that they have no conflict of interest.

\section{Acknowledgments}

This work was supported by the Basic Science Research Program through the National Research Foundation of Korea (NRF) funded by the Ministry of Education (2014R1A1A2055872).

\section{REFERENCES}

1. Iles L, Pfluger H, Phrommintikul A, Cherayath J, Aksit P, Gupta SN, et al. Evaluation of diffuse myocardial fibrosis in heart failure with cardiac magnetic resonance contrast-enhanced T1 mapping. J Am Coll Cardiol 2008; 52:1574-1580.

2. Miller CA, Naish JH, Bishop P, Coutts G, Clark D, Zhao S, et al. Comprehensive validation of cardiovascular magnetic resonance techniques for the assessment of myocardial extracellular volume. Circ Cardiovasc Imaging 2013;6:373-383.

3. aus dem Siepen F, Buss SJ, Messroghli D, Andre F, Lossnitzer D, Seitz S, et al. T1 mapping in dilated cardiomyopathy with cardiac magnetic resonance: quantification of diffuse myocardial fibrosis and comparison with endomyocardial biopsy. Eur Heart J Cardiovasc Imaging 2015;16:210-216.

4. Puntmann VO, Peker E, Chandrashekhar Y, Nagel E. T1 Mapping in characterizing myocardial disease: a comprehensive review. Circ Res 2016;119: 277-299.

5. Messroghli DR, Plein S, Higgins DM, Walters K, Jones TR, Ridgway JP, et al. Human myocardium: single-breath-hold MR T1 mapping with high spatial resolution--reproducibility study. Radiology 2006;238:1004-1012.

6. Dabir D, Child N, Kalra A, Rogers T, Gebker R, Jabbour A, et al. Reference values for healthy human myocardium using a T1 mapping methodology: results from the International T1 Multicenter cardiovascular magnetic resonance study. J Cardiovasc Magn Reson 2014;16:69.

7. Taylor AJ, Salerno M, Dharmakumar R, Jerosch-Herold M. T1 Mapping: basic techniques and clinical applications. JACC Cardiovasc Imaging 2016; 9:67-81.

8. Lurz JA, Luecke C, Lang D, Besler C, Rommel KP, Klingel K, et al. CMRderived extracellular volume fraction as a marker for myocardial fibrosis: the importance of coexisting myocardial inflammation. JACC Cardiovasc Imaging 2017 Apr 7 [Epub ahead of print]. https://doi.org/10.1016/j. jcmg.2017.01.025

9. Captur G, Gatehouse P, Keenan KE, Heslinga FG, Bruehl R, Prothmann M, et al. A medical device-grade T1 and ECV phantom for global T1 mapping quality assurance-the T1 mapping and ECV standardization in cardiovascular magnetic resonance (T1MES) program. J Cardiovasc Magn Reson 2016;18:58.

10. Costello BT, Springer F, Hare JL, Gerche A, Iles L, Ellims AH, et al. SASHA versus ShMOLLI: a comparison of T1 mapping methods in health and dilated cardiomyopathy at 3 T. Int J Cardiovasc Imaging 2017 Jun 6 [Epub ahead of print]. https://doi.org/10.1007/s10554-017-1134-y.

11. Moon JC, Messroghli DR, Kellman P, Piechnik SK, Robson MD, Ugander $\mathrm{M}$, et al. Myocardial T1 mapping and extracellular volume quantification: a Society for Cardiovascular Magnetic Resonance (SCMR) and CMR Working Group of the European Society of Cardiology consensus statement. J Cardiovasc Magn Reson 2013;15:92.

12. Choi EY, Hwang SH, Yoon YW, Park CH, Paek MY, Greiser A, et al. Correction with blood $\mathrm{T} 1$ is essential when measuring post-contrast myocardial $\mathrm{T} 1$ value in patients with acute myocardial infarction. J Cardiovasc Magn Reson 2013;15:11.

13. Treibel TA, Fontana M, Maestrini V, Castelletti S, Rosmini S, Simpson J, et al. Automatic measurement of the myocardial interstitium: synthetic extracellular volume quantification without hematocrit sampling. JACC Cardiovasc Imaging 2016;9:54-63.

14. Piechnik SK, Ferreira VM, Lewandowski AJ, Ntusi NA, Banerjee R, Holloway $\mathrm{C}$, et al. Normal variation of magnetic resonance $\mathrm{T} 1$ relaxation times in the human population at $1.5 \mathrm{~T}$ using ShMOLLI. J Cardiovasc Magn Reson 2013;15:13.

15. Liu CY, Liu YC, Wu C, Armstrong A, Volpe GJ, van der Geest RJ, et al. Evaluation of age-related interstitial myocardial fibrosis with cardiac magnetic resonance contrast-enhanced T1 mapping: MESA (Multi-Ethnic Study of Atherosclerosis). J Am Coll Cardiol 2013;62:1280-1287.

16. von Knobelsdorff-Brenkenhoff F, Prothmann M, Dieringer MA, Wassmuth R, Greiser A, Schwenke C, et al. Myocardial T1 and T2 mapping at 3 T: reference values, influencing factors and implications. J Cardiovasc Magn Reson 2013;15:53.

17. Yi CJ, Wu CO, Tee M, Liu CY, Volpe GJ, Prince MR, et al. The association between cardiovascular risk and cardiovascular magnetic resonance measures of fibrosis: the Multi-Ethnic Study of Atherosclerosis (MESA). J Cardiovasc Magn Reson 2015;17:15.

18. Bulluck H, Bryant JA, Tan JZ, Go YY, Le TT, Tan RS, et al. Gender differences in native myocardial $\mathrm{T} 1$ in a healthy chinese volunteer cohort. Cardiovasc Imaging Asia 2017;1:110-115.

19. Mascherbauer J, Marzluf BA, Tufaro C, Pfaffenberger S, Graf A, Wexberg P, et al. Cardiac magnetic resonance postcontrast $\mathrm{T} 1$ time is associated with outcome in patients with heart failure and preserved ejection fraction. Circ Cardiovasc Imaging 2013;6:1056-1065.

20. Schelbert EB, Piehler KM, Zareba KM, Moon JC, Ugander M, Messroghli DR, et al. Myocardial fibrosis quantified by extracellular volume is associated with subsequent hospitalization for heart failure, death, or both across the spectrum of ejection fraction and heart failure stage. J Am Heart Assoc 2015;4:e002613.

21. Duca F, Kammerlander AA, Zotter-Tufaro C, Aschauer S, Schwaiger ML, Marzluf BA, et al. Interstitial fibrosis, functional status, and outcomes in heart failure with preserved ejection fraction: insights from a prospective cardiac magnetic resonance imaging study. Circ Cardiovasc Imaging 2016;9:e05277. 
22. Bulluck H, Rosmini S, Abdel-Gadir A, White SK, Bhuva AN, Treibel TA, et al. Automated extracellular volume fraction mapping provides insights into the pathophysiology of left ventricular remodeling post-reperfused ST-Elevation myocardial infarction. J Am Heart Assoc 2016;5:e003555.

23. Carrick D, Haig C, Rauhalammi S, Ahmed N, Mordi I, McEntegart M, et al. Prognostic significance of infarct core pathology revealed by quantitative non-contrast in comparison with contrast cardiac magnetic resonance imaging in reperfused ST-elevation myocardial infarction survivors. Eur Heart J 2016;37:1044-1059.

24. Bonow RO, Maurer G, Lee KL, Holly TA, Binkley PF, Desvigne-Nickens $\mathrm{P}$, et al. Myocardial viability and survival in ischemic left ventricular dysfunction. N Engl J Med 2011;364:1617-1625.

25. Velazquez EJ, Lee KL, Jones RH, Al-Khalidi HR, Hill JA, Panza JA, et al. Coronary-artery bypass surgery in patients with ischemic cardiomyopathy. N Engl J Med 2016;374:1511-1520.

26. Gerber BL, Rousseau MF, Ahn SA, le Polain de Waroux JB, Pouleur AC, Phlips T, et al. Prognostic value of myocardial viability by delayed-enhanced magnetic resonance in patients with coronary artery disease and low ejection fraction: impact of revascularization therapy. J Am Coll Cardiol 2012; 59:825-835.

27. Chen Z, Sohal M, Voigt T, Sammut E, Tobon-Gomez C, Child N, et al. Myocardial tissue characterization by cardiac magnetic resonance imaging using T1 mapping predicts ventricular arrhythmia in ischemic and non-ischemic cardiomyopathy patients with implantable cardioverterdefibrillators. Heart Rhythm 2015;12:792-801.

28. Gramze NL, Shah DJ. Is there a need to assess myocardial viability in patients presenting with heart failure? Curr Opin Cardiol 2016;31:501-509.

29. Chan RH, Maron BJ, Olivotto I, Pencina MJ, Assenza GE, Haas T, et al. Prognostic value of quantitative contrast-enhanced cardiovascular magnetic resonance for the evaluation of sudden death risk in patients with hypertrophic cardiomyopathy. Circulation 2014;130:484-495.

30. Bruder O, Wagner A, Jensen CJ, Schneider S, Ong P, Kispert EM, et al. Myocardial scar visualized by cardiovascular magnetic resonance imaging predicts major adverse events in patients with hypertrophic cardiomyopathy. J Am Coll Cardiol 2010;56:875-887.

31. McLellan AJ, Ellims AH, Prabhu S, Voskoboinik A, Iles LM, Hare JL, et al. Diffuse ventricular fibrosis on cardiac magnetic resonance imaging associates with ventricular tachycardia in patients with hypertrophic cardiomyopathy. J Cardiovasc Electrophysiol 2016;27:571-580.

32. Edwards NC, Teoh JK, Steeds RP. Hypertrophic cardiomyopathy and Anderson-Fabry disease: unravelling septal hypertrophy with T1-mapping CMR. Eur Heart J 2014;35:1896.

33. Pica S, Sado DM, Maestrini V, Fontana M, White SK, Treibel T, et al. Reproducibility of native myocardial T1 mapping in the assessment of Fabry disease and its role in early detection of cardiac involvement by cardiovascular magnetic resonance. J Cardiovasc Magn Reson 2014;16:99.

34. Sado DM, White SK, Piechnik SK, Banypersad SM, Treibel T, Captur G, et al. Identification and assessment of Anderson-Fabry disease by cardiovascular magnetic resonance noncontrast myocardial T1 mapping. Circ Cardiovasc Imaging 2013;6:392-398.

35. Alam MH, Auger D, Smith GC, He T, Vassiliou V, Baksi AJ, et al. T1 at 1.5T and $3 \mathrm{~T}$ compared with conventional $\mathrm{T} 22^{*}$ at $1.5 \mathrm{~T}$ for cardiac siderosis. J Cardiovasc Magn Reson 2015;17:102.

36. Hinojar R, Varma N, Child N, Goodman B, Jabbour A, Yu CY, et al. T1 mapping in discrimination of hypertrophic phenotypes: hypertensive heart disease and hypertrophic cardiomyopathy: findings from the international T1 multicenter cardiovascular magnetic resonance study. Circ Cardiovasc Imaging 2015;8:e003285.

37. Swoboda PP, McDiarmid AK, Erhayiem B, Broadbent DA, Dobson LE, Garg P, et al. Assessing myocardial extracellular volume by T1 mapping to distinguish hypertrophic cardiomyopathy from athlete's heart. J Am Coll Cardiol 2016;67:2189-2190.

38. Ellims AH, Iles LM, Ling LH, Chong B, Macciocca I, Slavin GS, et al. A comprehensive evaluation of myocardial fibrosis in hypertrophic cardiomyopathy with cardiac magnetic resonance imaging: linking genotype with fibrotic phenotype. Eur Heart J Cardiovasc Imaging 2014;15:11081116.

39. Di Marco A, Anguera I, Schmitt M, Klem I, Neilan TG, White JA, et al. Late gadolinium enhancement and the risk for ventricular arrhythmias or sudden death in dilated cardiomyopathy: systematic review and metaanalysis. JACC Heart Fail 2017;5:28-38.

40. Yingchoncharoen T, Jellis C, Popovic ZB, Wang L, Gai N, Levy WC, et al. Focal fibrosis and diffuse fibrosis are predictors of reversed left ventricular remodeling in patients with non-ischemic cardiomyopathy. Int J Cardiol 2016;221:498-504.

41. Yoon JH, Son JW, Chung H, Park CH, Kim YJ, Chang HJ, et al. Relationship between myocardial extracellular space expansion estimated with post-contrast T1 mapping MRI and left ventricular remodeling and neurohormonal activation in patients with dilated cardiomyopathy. Korean J Radiol 2015;16:1153-1162.

42. Barison A, Del Torto A, Chiappino S, Aquaro GD, Todiere G, Vergaro G, et al. Prognostic significance of myocardial extracellular volume fraction in nonischaemic dilated cardiomyopathy. J Cardiovasc Med (Hagerstown) 2015;16:681-687.

43. Chen Z, Sohal M, Sammut E, Child N, Jackson T, Claridge S, et al. Focal but not diffuse myocardial fibrosis burden quantification using cardiac magnetic resonance imaging predicts left ventricular reverse modeling following cardiac resynchronization therapy. J Cardiovasc Electrophysiol 2016;27:203-209.

44. Puntmann VO, Carr-White G, Jabbour A, Yu CY, Gebker R, Kelle S, et al. T1-mapping and outcome in nonischemic cardiomyopathy: all-cause mortality and heart failure. JACC Cardiovasc Imaging 2016;9:40-50.

45. Fontana M, Banypersad SM, Treibel TA, Maestrini V, Sado DM, White SK, et al. Native T1 mapping in transthyretin amyloidosis. JACC Cardiovasc Imaging 2014;7:157-165.

46. Karamitsos TD, Piechnik SK, Banypersad SM, Fontana M, Ntusi NB, Ferreira VM, et al. Noncontrast T1 mapping for the diagnosis of cardiac amyloidosis. JACC Cardiovasc Imaging 2013;6:488-497.

47. Robbers LF, Baars EN, Brouwer WP, Beek AM, Hofman MB, Niessen HW, et al. T1 mapping shows increased extracellular matrix size in the myocardium due to amyloid depositions. Circ Cardiovasc Imaging 2012;5:423426.

48. Martinez-Naharro A, Abdel-Gadir A, Treibel TA, Zumbo G, Knight DS, Rosmini S, et al. CMR-verified regression of cardiac AL amyloid after chemotherapy. JACC Cardiovasc Imaging 2017 Apr 7 [Epub ahead of print]. https://doi.org/10.1016/j.jcmg.2017.02.012.

49. Banypersad SM, Fontana M, Maestrini V, Sado DM, Captur G, Petrie A, et al. T1 mapping and survival in systemic light-chain amyloidosis. Eur Heart J 2015;36:244-251.

50. Greulich S, Kitterer D, Latus J, Aguor E, Steubing H, Kaesemann P, et al. Comprehensive cardiovascular magnetic resonance assessment in patients with sarcoidosis and preserved left ventricular ejection fraction. Circ Cardiovasc Imaging 2016;9:e005022.

51. Ling LH, Kalman JM, Ellims AH, Iles LM, Medi C, Sherratt C, et al. Diffuse ventricular fibrosis is a late outcome of tachycardia-mediated cardiomyopathy after successful ablation. Circ Arrhythm Electrophysiol 2013;6:697-704.

52. Luetkens JA, Homsi R, Dabir D, Kuetting DL, Marx C, Doerner J, et al. Comprehensive cardiac magnetic resonance for short-term follow-up in acute myocarditis. J Am Heart Assoc 2016;5:e003603.

53. von Knobelsdorff-Brenkenhoff F, Schüler J, Dogangüzel S, Dieringer MA, Rudolph A, Greiser A, et al. Detection and monitoring of acute myocarditis applying quantitative cardiovascular magnetic resonance. Circ Cardiovasc Imaging 2017;10:e005242.

54. Barone-Rochette G, Piérard S, De Meester de Ravenstein C, Seldrum S, Melchior J, Maes F, et al. Prognostic significance of LGE by CMR in aortic stenosis patients undergoing valve replacement. J Am Coll Cardiol 2014; 64:144-154.

55. Dweck MR, Joshi S, Murigu T, Alpendurada F, Jabbour A, Melina G, et al. Midwall fibrosis is an independent predictor of mortality in patients with 
aortic stenosis. J Am Coll Cardiol 2011;58:1271-1279.

56. Nadjiri J, Nieberler H, Hendrich E, Will A, Pellegrini C, Husser O, et al. Prognostic value of T1-mapping in TAVR patients: extra-cellular volume as a possible predictor for peri- and post-TAVR adverse events. Int J Cardiovasc Imaging 2016;32:1625-1633.

57. Kockova R, Kacer P, Pirk J, Maly J, Sukupova L, Sikula V, et al. Native T1 relaxation time and extracellular volume fraction as accurate markers of diffuse myocardial fibrosis in heart valve disease-comparison with targeted left ventricular myocardial biopsy. Circ J 2016;80:1202-1209.

58. Lee SP, Lee W, Lee JM, Park EA, Kim HK, Kim YJ, et al. Assessment of diffuse myocardial fibrosis by using MR imaging in asymptomatic patients with aortic stenosis. Radiology 2015;274:359-369.

59. Chin CW, Everett RJ, Kwiecinski J, Vesey AT, Yeung E, Esson G, et al. Myocardial fibrosis and cardiac decompensation in aortic stenosis. JACC Cardiovasc Imaging 2016 Dec 8 [Epub ahead of print]. https://doi.org/10.1016/ j.jcmg.2016.10.007.

60. Basso C, Perazzolo Marra M, Rizzo S, De Lazzari M, Giorgi B, Cipriani A, et al. Arrhythmic mitral valve prolapse and sudden cardiac death. Circulation 2015;132:556-566.

61. Chaikriangkrai K, Lopez-Mattei JC, Lawrie G, Ibrahim H, Quinones MA, Zoghbi W, et al. Prognostic value of delayed enhancement cardiac magnetic resonance imaging in mitral valve repair. Ann Thorac Surg 2014;98: 1557-1563.

62. Edwards NC, Moody WE, Yuan M, Weale P, Neal D, Townend JN, et al. Quantification of left ventricular interstitial fibrosis in asymptomatic chronic primary degenerative mitral regurgitation. Circ Cardiovasc Imag- ing 2014;7:946-953.

63. Bui AH, Roujol S, Foppa M, Kissinger KV, Goddu B, Hauser TH, et al. Diffuse myocardial fibrosis in patients with mitral valve prolapse and ventricular arrhythmia. Heart 2017;103:204-209.

64. Nishimura RA, Otto CM, Bonow RO, Carabello BA, Erwin JP 3rd, Guyton RA, et al. $2014 \mathrm{AHA} / \mathrm{ACC}$ guideline for the management of patients with valvular heart disease: executive summary: a report of the American College of Cardiology/American Heart Association Task Force on Practice Guidelines. J Am Coll Cardiol 2014;63:2438-2488.

65. Lin Y, Yang SG, Chen H, Zhang HQ, Wang CS. [The predictive value of DE-CMR in patients with severe chronic aortic regurgitation and extremely dilated left ventricular chamber]. Zhonghua Wai Ke Za Zhi 2012;50: 1087-1090.

66. McAlindon E, Pufulete M, Lawton C, Angelini GD, Bucciarelli-Ducci C. Quantification of infarct size and myocardium at risk: evaluation of different techniques and its implications. Eur Heart J Cardiovasc Imaging 2015;16:738-746

67. Mikami Y, Kolman L, Joncas SX, Stirrat J, Scholl D, Rajchl M, et al. Accuracy and reproducibility of semi-automated late gadolinium enhancement quantification techniques in patients with hypertrophic cardiomyopathy. J Cardiovasc Magn Reson 2014;16:85.

68. Daftari Besheli L, Aran S, Shaqdan K, Kay J, Abujudeh H. Current status of nephrogenic systemic fibrosis. Clin Radiol 2014;69:661-668.

69. Abdel-Gadir A, Treibel T, Moon J. Myocardial T1 mapping: where are we now and where are we going? Res Rep Clin Cardiol 2014;5:339. 